\title{
Leakage Characteristic of Helical Groove Seal Designed in Reactor Coolant Pump
}

\author{
Meng Zhang, ${ }^{1}$ Xiao-fang Wang, ${ }^{1}$ Sheng-li Xu, ${ }^{1}$ and Shuo Yin ${ }^{1,2}$ \\ ${ }^{1}$ School of Energy and Power Engineering, Dalian University of Technology, No. 2, Linggong Road, Liaoning, Dalian 116024, China \\ ${ }^{2}$ Laboratoire d'Etudes et de Recherches sur les Matériaux, les Procédés et les Surfaces (LERMPS), Université de Technologie \\ de Belfort-Montbéliard, Site de Sévenans, 90010 Belfort Cedex, France
}

Correspondence should be addressed to Meng Zhang, zmdlut@qq.com

Received 30 August 2012; Revised 13 November 2012; Accepted 14 November 2012

Academic Editor: Seyed G. Saddoughi

Copyright (C 2012 Meng Zhang et al. This is an open access article distributed under the Creative Commons Attribution License, which permits unrestricted use, distribution, and reproduction in any medium, provided the original work is properly cited.

\begin{abstract}
Helical groove seal is designed in reactor coolant pump to control the leakage along the front surface of the impeller face due to its higher resistance than the circumferentially grooved seal. The flow and the friction factors in helical groove seals are predicted by employing a commercial CFD code, FLUENT. The friction factors of the helical groove seals with helix angles varying from $20 \mathrm{deg}$ to $50 \mathrm{deg}$, at a range of rotational speed and axial Reynolds number, were, respectively, calculated. For the helically grooved stator with the helix angle greater than $20 \mathrm{deg}$, the leakage shows an upward trend with the helix angle. The circumferentially grooved stator has a lower resistance to leakage than the $20 \mathrm{deg}$ and $30 \mathrm{deg}$ stators. It can be predicated that, for a bigger helix angle, the friction factor increases slightly with an increase in high axial Reynolds number, which arises from the high-pressure operation condition, and the friction factor is generally sensitive to changes in the helix angle in this operation condition. The study lays the theoretical foundation for liquid seal design of reactor coolant pump and future experimental study to account for the high-pressure condition affecting the leakage characteristic.
\end{abstract}

\section{Introduction}

Recently, it has been recognized that the leakage flow of highly effective seal is the key point of nuclear plant safety. Leakage flow characteristics of the seal in the nuclear equipment were investigated by several researchers.

In high temperature gas-cooled reactor (HTGR) core, the prevention of leakage flows of coolant gas is important for a thermal hydraulic design; the seal mechanism for the core was researched by Kaburaki and Takizuka [1,2]. The leakage flows through the gaps between core support blocks were restricted because the gap between the core support blocks was still kept wide during the reactor operation to prevent the interaction of the blocks.

The improvements in the leakage along the front surface of the impeller face are the key point of reactor coolant pump (RCP) reliability. Leakage control in the clearance is the most important problem to be solved, which can increase the reliability and efficiency of RCP and, thus, assure the satisfactory operation. If the leakage is out of control, the leakage flow will disturb the main flow at the inlet of the impeller, and then the circulation area will decrease. It will lead to a decrease of the hydraulic efficiency of RCP. Once the pump operates on a low head due to the larger leakage, there will be a serious danger of water coolant undersupply, which leads to excess reactor core temperature.

To gain a better leakage control, circumferentially grooved seal is commonly used in the pump. But its performance in the high-pressure condition is unsatisfied. To fit in the extreme condition, helical groove seal is designed in reactor coolant pump to obtain a higher resistance to leakage than the circumferentially grooved seal. High rotational speed yields backflow along the groove-forward inlet and reduction in the average axial and circumferential fluid velocity. Beyond that, the helically grooved stator application is to remove any impurities through the groove path.

However, helically grooved seals have not been investigated thoroughly because of their complex characteristics. Bootsma [3] investigated the spiral-groove bearings by employing a turbulence model, which was similar to Hirs [4]. 




Figure 1: Helically grooved stator.

Kim and Childs' [5] model evaluated a bulk-flow analysis for helical groove seals with grooved rotors and grooved stators. The analysis also incorporated both Hirs [4] turbulent lubrication theory and "fine-groove" theory. The governing equations were expanded in the eccentricity ratio to yield zeroth and first-order perturbation solutions. Additionally, Walowit [6] developed a fine-groove-based analysis for laminar helical groove seals; however, it was not suitable for the highly turbulent flow.

Kim and Childs [5] predicted that the helically grooved stator is more stable than the helically grooved rotor. But the helically grooved stator configuration had higher leakage rate than the helically grooved rotor configuration due to its significantly lower power consumption. Besides, Iwatsubo et al. [7] reported that the formation of the negative crosscoupled stiffness coefficients was the reason why helically grooved stator was more stable.

Some studies were presented to determine the leakage characteristics of helical groove seals, which were just operated in the low-pressure condition. Kanki and Kawakami [8] reported that the leakage flow of the helical groove seal was less than that of the plain seal. The effect of the helical groove was predominant in the high-speed region. Iwatsubo et al. [9] performed a systematic analysis on turbulent annular seals with a helically grooved rotor. As the journal rotating frequency increased, the leakage flow decreased. Zero net leakage flow was possible at a particular rotating frequency. The leakage data and friction factors were presented for helical groove seals by Childs et al. [10]. The test results supported the conclusion that the number of grooves and the leakage rates increased steadily with increasing the helix angles in the low pressure.

Gowda and Prabhu [11] present theoretical investigations of high-pressure annular seal that deal with the steadystate mass flow rate, labyrinth seal-influence coefficients, and unbalance response of a high-pressure fuel turbo pump.

Before this paper, the leakage characteristic of the helical groove seal in the pressure higher than $17 \mathrm{MPa}$ condition has not been researched. To fit in the extreme condition, helical groove seal is designed to control the leakage in reactor coolant pump. To obtain helical groove seal with highresistance, this paper is initiated to predict a high friction factor for a proper choice of the helix angle $\alpha$ in the high pressure condition.

\section{Computational Descriptions}

2.1. Model. A three-dimensional CFD model is used in this study to calculate the steady incompressible flow within the seal. Water is employed as the sealing medium, and the temperature is treated as a constant value. The leakage characteristics are determined by employing the standard $\kappa-\mathcal{E}$ turbulence model, and CFD analysis of the seal is performed by ANSYS FLUENT.

The turbulence kinetic energy, $k$, and its rate of dissipation, $\varepsilon$, are obtained from the following transport equations:

$$
\begin{aligned}
\frac{\partial}{\partial t}(\rho k)+\frac{\partial}{\partial x_{i}}\left(\rho k u_{i}\right)= & \frac{\partial}{\partial x_{j}}\left[\left(\mu+\frac{\mu_{t}}{\sigma_{k}}\right) \frac{\partial k}{\partial x_{j}}\right] \\
& +G_{k}+G_{b}-\rho \varepsilon-Y_{M}+S_{k}, \\
\frac{\partial}{\partial t}(\rho \varepsilon)+\frac{\partial}{\partial x_{i}}\left(\rho \varepsilon u_{i}\right)= & \frac{\partial}{\partial x_{j}}\left[\left(\mu+\frac{\mu_{t}}{\sigma_{\varepsilon}}\right) \frac{\partial \epsilon}{\partial x_{j}}\right] \\
& +C_{1 \varepsilon} \frac{\varepsilon}{k}\left(G_{k}+C_{3 \varepsilon} G_{b}\right)-C_{2 \varepsilon} \rho \frac{\varepsilon^{2}}{k}+S_{\varepsilon},
\end{aligned}
$$

where

$$
\mu_{t}=\rho C_{\mu} \frac{k^{2}}{\varepsilon} .
$$

In these equations, $G_{k}$ represents the generation of turbulence kinetic energy due to the mean velocity gradients; $G_{b}$ is the generation of turbulence kinetic energy due to buoyancy; $Y_{M}$ represents the contribution of the fluctuating dilatation in compressible turbulence to the overall dissipation rate. The model constants $C_{1 \varepsilon}=1.44, C_{2 \varepsilon}=1.92, C_{\mu}=0.09$, and $\sigma_{k}=1.0, \sigma_{\varepsilon}=1.3$ are the turbulent Prandtl numbers for $k$ and $\varepsilon$, respectively. $S_{k}$ and $S_{\varepsilon}$ are user-defined source terms [12]. The capability of the $\kappa-\varepsilon$ turbulence model for the grooved liquid annular seal has been validated by comparison between the computed results and the threedimensional laser Doppler anemometer measurements [13].

A second order discretization scheme is used for the pressure, density, and momentum terms. First-order upwind scheme is used for turbulent dissipation rate terms. Resolving boundary layers, standard wall function is used to model the viscous effects in the near-wall regions. The convergence criterion for continuity, velocity, $\kappa$, and $\varepsilon$ equations is below $10^{-5}$. Parametric study is conducted over a wide range of Reynolds number (90000-245000). Pressure outlet boundary is maintained at constant value, and the inlet pressure is changed to achieve different Reynolds number.

2.2. Dimensions and Conditions. A typical helically grooved stator annular seal is illustrated in Figure 1. The seals used in this paper provide smooth rotor and helically grooved stator. 


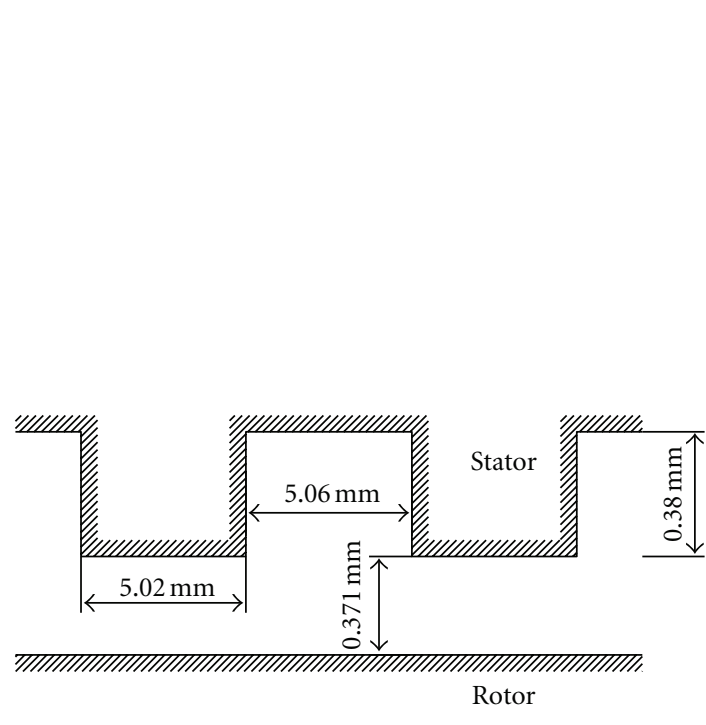

(a) Groove cross section (not scaled)

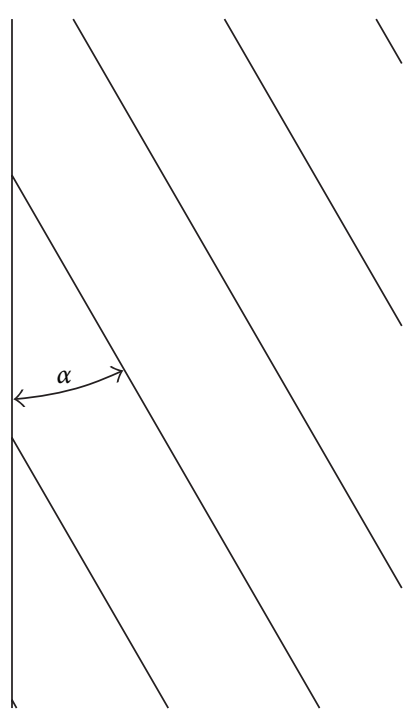

(b) Helix angle $\alpha$

Figure 2: Groove dimension.

The helical groove results in fluid rotation in a direction opposite to the shaft rotation.

The helix angle $\alpha$ is set to oppose the fluid rotation and yields a reduction in the average axial and circumferential fluid velocity. The angle $\alpha$ can vary from zero (circumferential grooving) to $90 \mathrm{deg}$ (axial grooving).

The five seal configurations were computed to evaluate the influence of helix angle $\alpha$ on the leakage characteristics. Figure 2 provides the seal nominal dimensions. Five helix angles, namely, 0, 20, 30, 40, and $50 \mathrm{deg}$, were computed. These seals maintain the same cross section as the inlet as shown in Figure 2(a). The seal length is $50 \mathrm{~mm}$, and the rotor diameter is $100 \mathrm{~mm}$. Computational results are presented for an outlet pressure of 17.1 MPa.

2.3. Mesh Generation. The 3D mesh applying the structured hexagonal cells for the land and groove is created using the commercial mesh generator Gambit. The 2D view for the inlet section of the helical groove seal mesh is defined as shown in Figure 3. A mesh independent density study is performed to investigate the effect of mesh density and to determine how fine a mesh is required to capture the important pressure physics. The mesh is refined in the radial direction and circumferential direction dependently. Figure 4 shows the effect of refining the mesh in the cross section on the inlet average pressure. The pressure varies less than $0.002 \%$ with increasing mesh density and is mesh independent. To obtain a better pressure prediction, maximum density mesh will be used in subsequent calculations.

Starting with the one node away from the wall, the mesh points are redistributed as the double-sided ratio 1.15 in the radial direction and 1.2 in the circumferential direction of the groove width. The near-wall mesh points are disturbed so as to maintain a smaller value $y^{+}$, resulting in improved wall shear stress and pressure prediction.

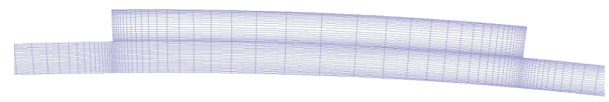

FIgure 3: 2D view for the inlet section mesh.



Figure 4: Mesh density study.

Law-of-the-wall formulations model the sharp pressure gradients near the wall and are used with standard $\kappa-\varepsilon$ turbulence model as follows:

$$
\begin{gathered}
U^{*}=y^{*} \quad \text { for } y^{*}<11.225, \\
U^{*}=\frac{1}{\kappa} \ln \left(E y^{*}\right) \quad \text { for } y^{*}>11.225,
\end{gathered}
$$

where

$$
U^{*} \equiv \frac{U_{P} C_{\mu}^{1 / 4} k_{P}^{1 / 2}}{\tau_{\omega} / \rho}
$$

is the dimensionless velocity. 


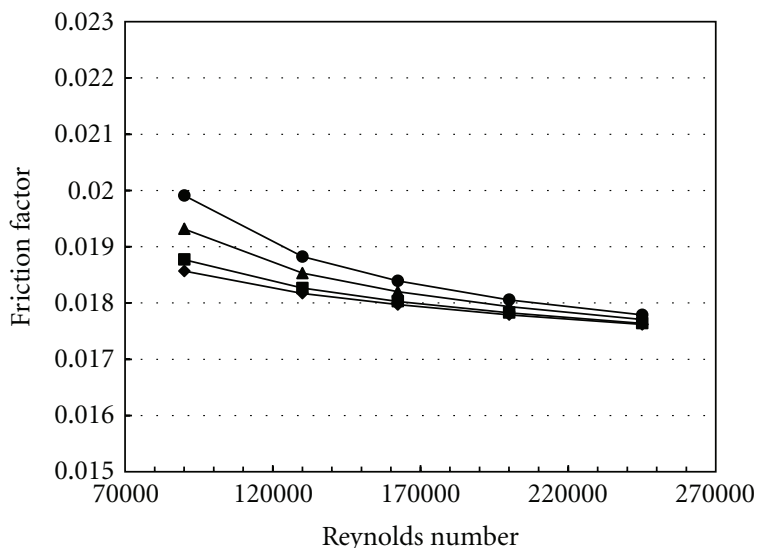

(a) 0 deg



(c) $30 \mathrm{deg}$

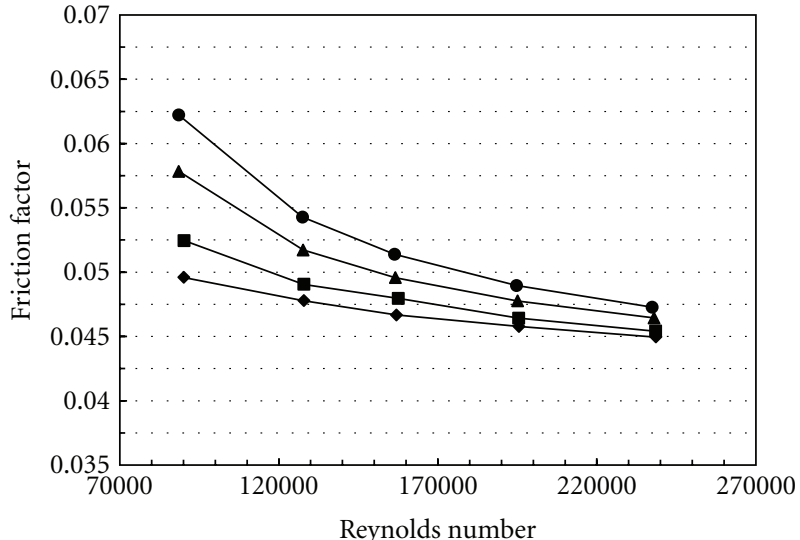

(b) $20 \mathrm{deg}$

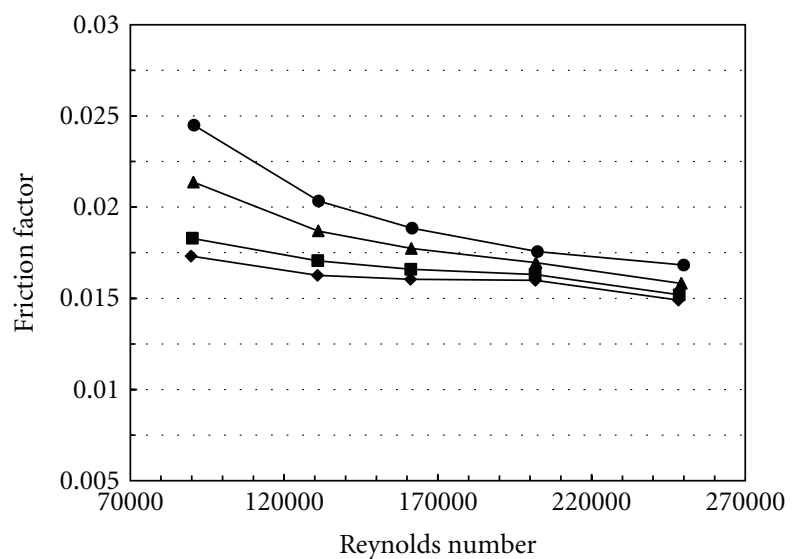

(d) $40 \mathrm{deg}$



(e) $50 \mathrm{deg}$

FIGURE 5: Friction factor for five helix angles.

Consider that

$$
y^{*} \equiv \frac{\rho C_{\mu}^{1 / 4} k_{P}^{1 / 2} y_{P}}{\mu}
$$

is the dimensionless distance from the wall, $C \mu=$ turbulent viscosity constant $(=0.09), \boldsymbol{\kappa}=$ von Kármán constant
$(=0.4187), E=$ empirical constant $(=9.793), U_{P}=$ mean velocity of the fluid at the near-wall node $P, k_{P}=$ turbulence kinetic energy at the near-wall node $P, y_{P}=$ distance from point $P$ to the wall, and $\mu=$ dynamic viscosity of the fluid.

The laws of the wall for mean velocity and pressure are based on the wall unit, $y^{*}$, rather than $y^{+}\left(\equiv \rho \mathrm{u}_{\tau} y / \mu\right)$. 
These quantities are approximately equal in equilibrium turbulent boundary layers [12].

\section{Results and Discussion}

Two faces are located about the midplane of the seal at 0.23 and 0.5 of the seal length. The pressure differential is defined as the pressure computed upstream and immediately inside the seal. The axial pressure gradient is defined by the two average pressure faces at $0.23 \mathrm{~L}$ and $0.5 \mathrm{~L}$. The seal length, $L$, is $50 \mathrm{~mm}$.

The friction factor definition reference of Childs et al. [10] is modified. The minimum clearance is replaced by the hydraulic diameter, because that is a better representation for the frictional head loss coefficient. The following definition is used for the friction factor developed in the seals:

$$
\lambda=-\frac{d P}{d Z} \cdot \frac{D}{2 \rho v^{2}},
$$

where $P$ is the static pressure, $Z$ is the axial seal coordinate, $D$ is the hydraulic diameter, $\rho$ is the density, and $v$ is the average axial velocity. Figure 5 illustrates the friction factor versus the axial Reynolds number, $\mathrm{Re}=\nu D \rho / \mu$, and the rotational speed for stators with the helix angle of $0,20,30,40$, and $50 \mathrm{deg}$.

3.1. Helix Angle. There are comparable representative resistance characteristics among the five models. As can be observed from Figure 5, for all helically grooved stators, the friction factor shows an upward trend with the helix angle reduction, because the seal with a smaller helix angle has less axial component flow and longer groove in favour of energy dissipation. And it becomes more sensitive to the rotational speed when the helix angle decreases. For the helically grooved stators, the friction factor generally decreases with the increasing axial Reynolds number. At the condition of low axial Reynolds number, it obviously drops monotonically with axial Reynolds number. At comparatively high axial Reynolds number, for $\alpha=30,40$, and $50 \mathrm{deg}$, the friction factor tends to converge to the same value with axial Reynolds number, and the friction factor even increases slightly with axial Reynolds number at the low rotational speed condition. The curve tends to get in self-simulated domain with axial Reynolds number higher than 250000.

3.2. Rotational Speed. As can be observed from Figure 5, for all helically grooved stator, the friction factor generally increases with increasing the running speed. Figure 6 shows the variation of the friction factor with the axial Reynolds number for all the stators at $1750 \mathrm{rpm} .20 \mathrm{deg}$ stator has higher resistance to leakage than the remaining stator. For the helix angle greater than $20 \mathrm{deg}$, the helically grooved stators leak increasingly more as the helix angle increases, because the leakage flow in the groove with greater helix angle has more axial component flow and shorter groove at the lack of energy dissipation. The circumferentially grooved stator has lower friction factor than the 20 and 30 deg stators because it cannot yield backflow along the groove-forward inlet.

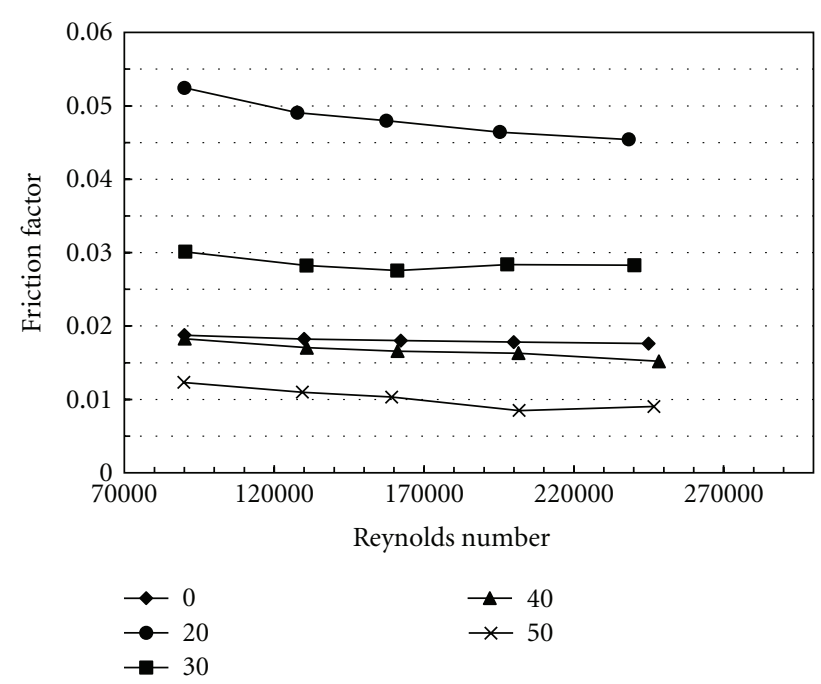

FIGURE 6: Friction factor for helically grooved stators at $1750 \mathrm{rpm}$ versus Re.

Figure 7 illustrates the friction factor for helically grooved stators at $4000 \mathrm{rpm}$ versus axial Reynolds number. It is clear that the 20 and $30 \mathrm{deg}$ stators have higher resistance to leakage than the circumferentially grooved stator. At low axial Reynolds number, $40 \mathrm{deg}$ stator surpasses the circumferential grooved stator in friction value due to the increment in the rotational speed. Increasing rotational speed yields more backflow along the groove forward inlet and reduction in the average axial and circumferential fluid velocity.

3.3. Flow Field. Figure 8 shows the pressure contour of the circumferentially grooved stator. It is clear that the pressure contour gradient vector of circumferential grooved stator is parallel to the rotor axis. Comparatively, in Figure 9, which shows the pressure contour of $20 \mathrm{deg}$ stator, it can be found that the stagnation area exists along the upwind surface of the groove due to the impingement of rotational fluid. Fluid rotation opposes the helix angle $\alpha$, and it yields a reduction in the average circumferential fluid velocity that ensures the seal stability. Figure 10 shows the pressure contour of $0.2 \mathrm{~L}$ cross section for four helix angles. The value range of the pressure becomes narrower, and the peak value declines as the helix angle increases. The stagnation region shrinks in area and moves to leeward as the helix angle increases. This fact influences the distribution of the turbulent kinetic energy, which can be found in Figure 11 showing the turbulent kinetic energy contour of $0.2 \mathrm{~L}$ cross section for

four helix angles.

The turbulent kinetic energy value is related to the energy dissipation. It is seen that the turbulent kinetic energy of $20 \mathrm{deg}$ stator is higher than any other stator, and the highly turbulent kinetic energy region existing on the left of the groove is the largest, which is in favour of energy dissipation. The highly turbulent kinetic energy region shrinks in area and moves to leeward as the helix angle increases. The highly turbulent kinetic energy region of the 


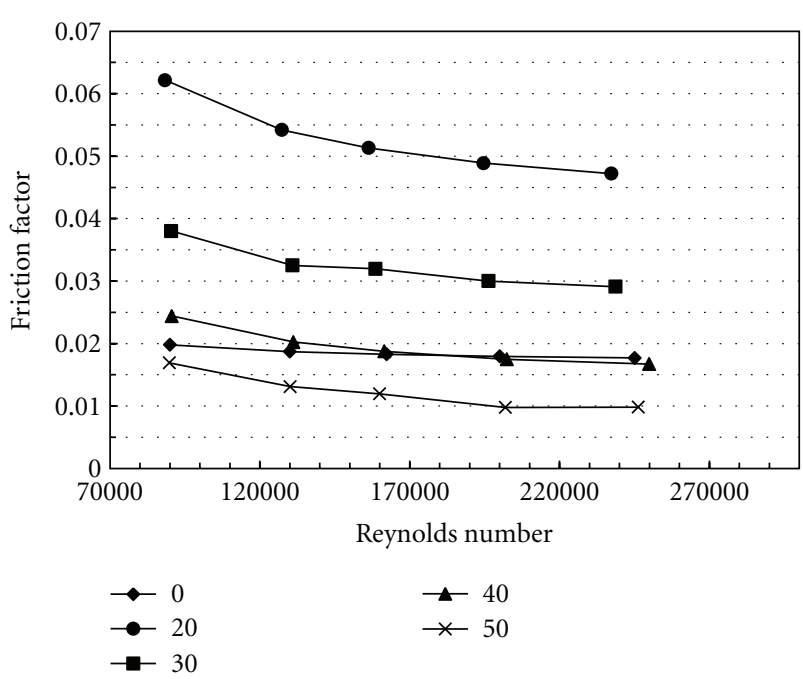

FIGURE 7: Friction factor for helically grooved stators at $4000 \mathrm{rpm}$ versus Re.

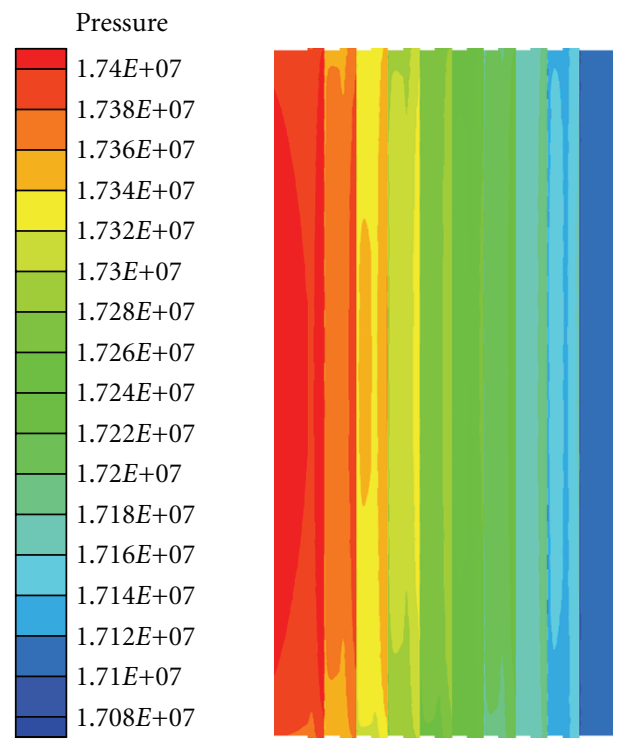

FIGURE 8: Pressure contour of circumferential grooved stator.

50 deg stator is the smallest, and the peak value is the lowest. It is speculated that the difference in friction factor among helically grooved stators is related to the relative location of the highly turbulent kinetic energy region in the groove and the turbulent kinetic energy value range.

\section{Conclusions}

(a) The friction factor shows an upward trend with the helix angle reduction, because the seal with a smaller helix angle has less axial component flow and longer groove in favour of energy dissipation. Helically grooved stators with helix angles greater than 20 deg leak increasingly more as the helix angle increases. The circumferentially grooved stator has a lower resistance to leakage than the $20 \mathrm{deg}$ and $30 \mathrm{deg}$

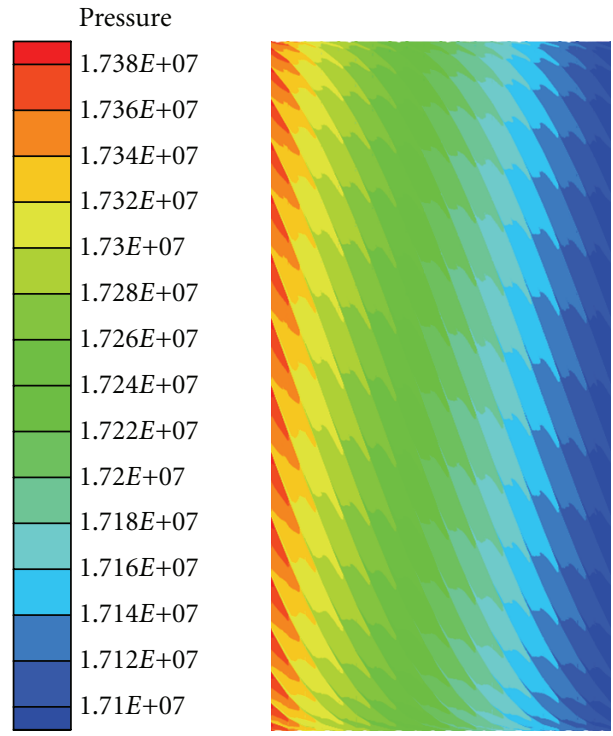

FIgURE 9: Pressure contour of 20 deg stator.

stators, thereby helical groove seal is designed better than the circumferentially grooved seal in reactor coolant pump.

(b) For all helically grooved stators, the friction factor generally increases with increasing the running speed. The friction factor is more sensitive to the rotational speed especially for the smaller helix angle stator.

(c) The friction factor generally decreases with axial Reynolds number. At Re lower than 160000, the friction factor drops monotonically with axial Reynolds number. At high Re, for $\alpha=30,40$, and $50 \mathrm{deg}$, the friction factor tends to converge to the same value with axial Reynolds number, especially for low rotational speed, and the friction factor increases slightly with axial Reynolds number. The curve tends to get in self-simulated domain with axial Reynolds number higher than 250000 .

(d) At $1750 \mathrm{rpm}, 20$ deg stator has much higher resistance to leakage than the circumferentially grooved stator; therefore, in reactor coolant pump, the helicallygrooved stator with significantly higher power consumption can be used as the axial seal to control backflow leakage along the front surface of the impeller face and reduce the leakage flow rate, while keeping the clearance comparable to that of a plain seal. Because a helical groove yields a backflow along the groove forward inlet, the other object of the application is to remove impurities through the groove path.

Besides, numerical studies are conducted to determine the basic characteristics of the helically grooved stator in high-pressure condition. The conclusions will be summarized for effective application in helical groove seals 


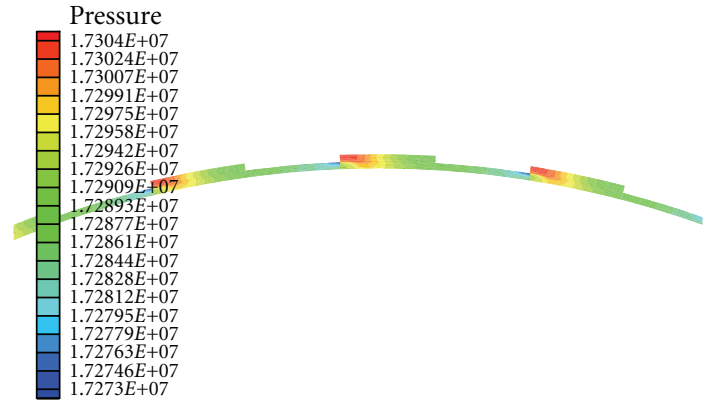

(a) $20 \mathrm{deg}$



(c) $40 \mathrm{deg}$

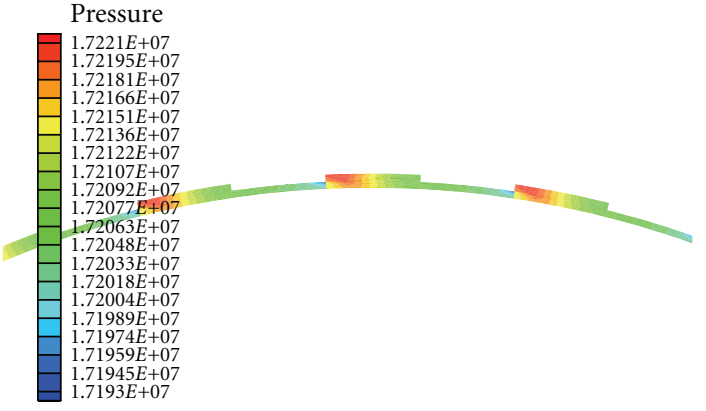

(b) $30 \mathrm{deg}$

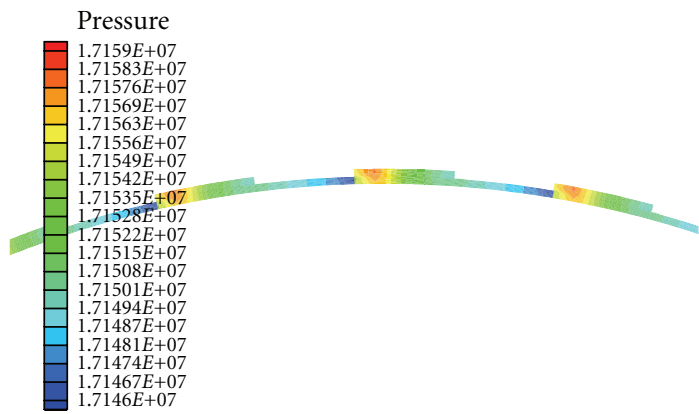

(d) $50 \mathrm{deg}$

FIgURe 10: Pressure contour of $0.2 L$ cross section for four helix angles.

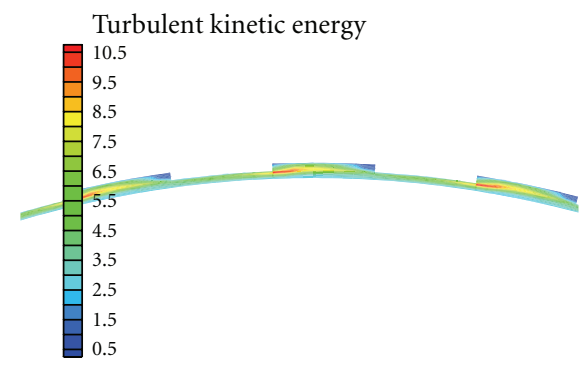

(a) $20 \mathrm{deg}$

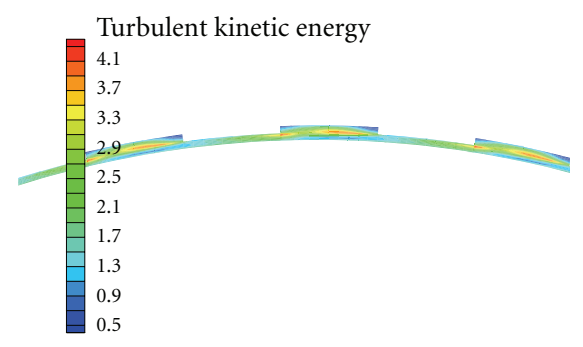

(c) $40 \mathrm{deg}$

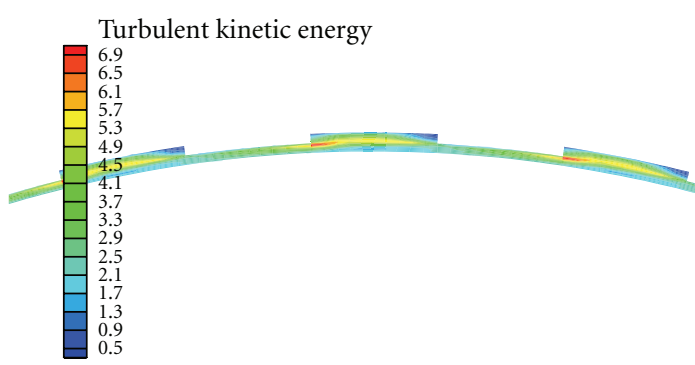

(b) $30 \mathrm{deg}$



(d) $50 \mathrm{deg}$

Figure 11: Contours of turbulent kinetic energy of $0.2 L$ cross section for four helix angles.

of RCP and contribute future experimental studies on this type of seal.

\section{Nomenclatures}

Re: Axial Reynolds number

$\alpha$ : Helix angle (deg) $\lambda$ : Friction factor

$P$ : Static pressure $(\mathrm{Pa})$

$L$ : Seal length $(\mathrm{m})$

$Z$ : Axial seal coordinate $(\mathrm{m})$

$D$ : Hydraulic diameter $(\mathrm{m})$

$\rho$ : Density $\left(\mathrm{kg} / \mathrm{m}^{3}\right)$

$v$ : Average axial velocity $(\mathrm{m} / \mathrm{s})$ 


$\begin{array}{ll}\mu: & \text { Dynamic viscosity }(\mathrm{Pa} \cdot \mathrm{s}) \\ \kappa: & \text { Turbulent kinetic energy }\left(\mathrm{m}^{2} / \mathrm{s}^{2}\right) \\ \varepsilon: & \text { Turbulent dissipation rate }\left(\mathrm{m}^{2} / \mathrm{s}^{3}\right) \\ C \mu: & \text { Turbulent viscosity constant } \\ \kappa: & \text { Von Kármán constant } \\ E: & \text { Empirical constant } \\ U_{P}: & \text { Mean velocity of the fluid at the near-wall } \\ & \text { node } P(\mathrm{~m} / \mathrm{s}) \\ k_{P}: & \text { Turbulence kinetic energy at the near-wall } \\ & \text { node } P\left(\mathrm{~m}^{2} / \mathrm{s}^{2}\right) \\ y_{P}: & \text { Distance from point } P \text { to the wall (m) } \\ G_{k}: & \text { Generation of turbulence kinetic energy } \\ & \text { due to the mean velocity gradients } \\ G_{b}: & \text { Generation of turbulence kinetic } \\ & \text { energy due to buoyancy } \\ \mathrm{Y}_{M}: & \text { Contribution of the fluctuating dilatation } \\ & \text { in compressible turbulence to the overall } \\ & \text { dissipation rate } \\ C_{1 \varepsilon}, C_{2 \varepsilon}, C_{3 \varepsilon}: & \text { Model constants for } \varepsilon \text { equations } \\ \sigma_{k}: & \text { Turbulent Prandtl number for } k \\ \sigma_{\varepsilon}: & \text { Turbulent Prandtl number for } \varepsilon \\ S_{k}: & \text { User-defined source term for } k \\ S_{\varepsilon}: & \text { User-defined source term for } \varepsilon .\end{array}$

\section{Acknowledgment}

The authors appreciate the financial support from the National Basic Research Program of China (973 Program).

\section{References}

[1] H. Kaburaki and T. Takizuka, "Leakage flow characteristics of highly effective graphite seal mechanism for HTGR core support blocks," Journal of Nuclear Science and Technology, vol. 25, no. 1, pp. 92-99, 1988.

[2] H. Kaburaki and T. Takizuka, "Leakage flow characteristics of seal mechanism for HTGR core support blocks," Journal of Nuclear Science and Technology, no. 9, pp. 742-747, 1987.

[3] J. Bootsma, Liquid-lubricated spiral-groove bearings [Ph.D. thesis], Technological University, Delft, The Netherlands, 1975.

[4] G. G. Hirs, "A bulk-flow theory for turbulence in lubricant films," ASME Journal of Lubrication Technology, vol. 95, no. 2, pp. 137-146, 1973.

[5] C.-H. Kim and D. W. Childs, "Analysis for rotordynamic coefficients of Helically-Grooved turbulent annular seals," ASME Journal of Tribology, vol. 109, no. 1, pp. 136-143, 1987.

[6] J. A. Walowit, "User's manual for computer code SPIRALG gas lubricated spiral grooved cylindrical and face seals," Tech. Rep. NAS3-25644, 1992.

[7] T. Iwatsubo, B. C. Sheng, and M. Ono, "Experiment of static and dynamic characteristics of spiral grooved seals, rotordynamic instability problems in high-performance turbomachinery," in Proceedings of a Workshop NASA CP No. 3122, pp. 223-234, A\&M University, Texas, Tex, USA, 1990.

[8] K. Kanki and T. Kawakami, "Experimental study on the static and dynamic characteristics of screw Grooved seals," Rotating Machinery Dynamics, vol. 1, pp. 273-278, 1987.

[9] T. Iwatsubo and B. S. Yang R Ibaraki, "Theoretical approach to obtaining dynamic characteristics of noncontacting spiralGrooved seals, Rotor-dynamic instability problems in high performance turbomachinery," in Proceedings of a Workshop NASA CP, 2443, pp. 155-188, A\&M University, Texas, Tex, USA, June 1986.

[10] D. W. Childs, S. A. Nolan, and J. J. Kilgore, "Test results for turbulent annular seals, using smooth rotors and helically grooved stators," Journal of Tribology, vol. 112, no. 2, pp. 254$258,1990$.

[11] D. R. Gowda and B. S. Prabhu, "High-pressure annular seal leakage and rotordynamics with application to turbomachinery," International Journal of Rotating Machinery, vol. 8, no. 6, pp. 403-411, 2002.

[12] ANSYS Inc., ANSYS FLUENT 12. 0 Theory Guide, ANSYS Inc., Canonsburg, Pa, USA, 2009.

[13] J. J. Moore and A. B. Palazzolo, "CFD comparison to 3D laser anemometer and rotordynamic force measurements for grooved liquid annular seals," Journal of Tribology, vol. 121, no. 2, pp. 306-314, 1999. 

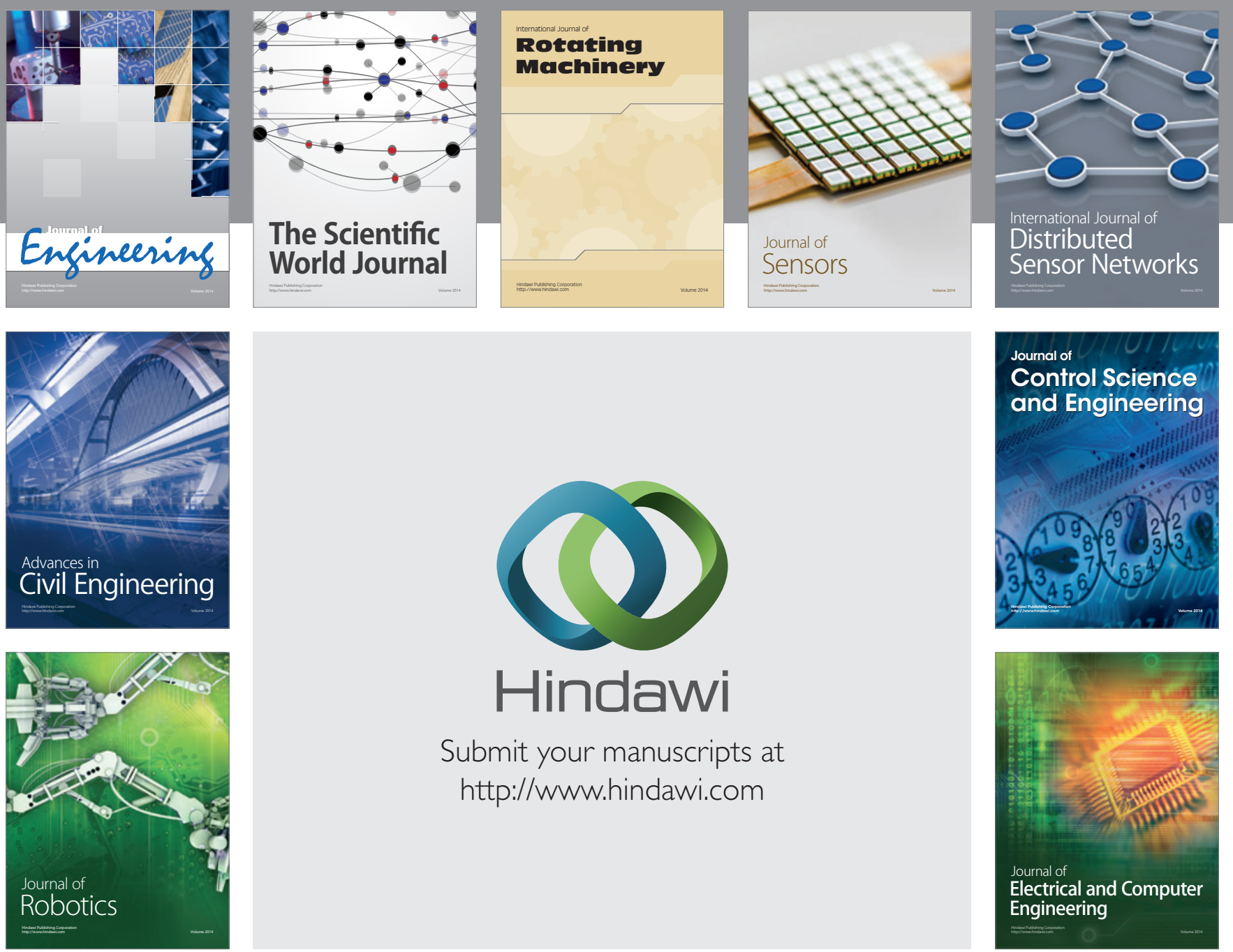

Submit your manuscripts at

http://www.hindawi.com
